extremely low in advanced renal failure; the concentration is normal or increased, however, in patients with early to moderate renal failure, in whom hypocalcaemia, secondary hyperparathyroidism, and defective bone mineralisation are often present. ${ }^{4}$ Furthermore, treatment with $1 \alpha, 25$-dihydroxy or $1 \alpha$-hydroxy vitamin $\mathrm{D}_{3}$ might alleviate skeletal pain, increase serum calcium concentration, suppress secondary hyperparathyroidism, and improve the skeletal lesions of osteitis fibrosa; results in patients with osteomalacia, however, were disappointing. ${ }^{5}$ The question remains, therefore, whether another metabolite of vitamin D, important for normal bone structure, is affected in renal failure. 24,25-Dihydroxy vitamin D may possibly play a part in normal bone formation. ${ }^{2}$ Our findings show that production of this metabolite is already impaired in early stages of renal failure. If low serum concentrations of 24,25 -dihydroxy vitamin $\mathrm{D}$ are causally related to the osteomalacia of chronic renal failure, treatment with both 1,25-dihydroxy and 24,25-dihydroxy vitamin D may be needed to prevent and heal renal osteodystrophy.

We thank Reuven Terdiman for his help in the statistical analysis. This study serves as part of the requirements for the MD degree for $L$ Leib at the Technion, Israel Institute of Technology, Faculty of Medicine.

${ }^{1}$ Mawer EB, Backhouse J, Taylor CM, Lumb GA, Stanbury SW. Failure of formation of 1,25-dihydroxycholecalciferol in chronic renal insufficiency. Lancet $1973 ; \mathrm{i}: 626-8$

${ }^{2}$ Ornoy A, Goodwin D, Noff D, Edelstein S. 24,25-dihydroxyvitamin D is a metabolite of vitamin $D$ essential for bone formation. Nature $1978 ; 276: 517-9$.

3 Weisman Y, Reiter E, Root A. Measurement of 24,25-dihydroxyvitamin $\mathrm{D}$ in sera of neonates and children. F Pediatr 1977;91:904-7.

4 Slatopolsky E, Gray R, Adams ND, et al. The pathogenesis of secondary hyperthyroidism in early renal failure. In: Norman AW, Schaefer K, Herrath DV, et al, eds. Vitamin $D$ basic research and its clinical application. Berlin and New York: W de Gruyter, 1979:1209-15.

${ }^{5}$ Pierides AM, Ellis HA, Simpson W, Dewar JH, Ward MK, Kerr DNS Variable response to long-term $1 \alpha$-hydroxycholecalciferol in haemodialysis osteodystrophy. Lancet 1976;i:1092-5.

(Accepted 19 May 1980)

Vitamins Research Laboratory, Municipal Government Medical

Centre, Tel-Aviv, Israel

Y WEISMAN, MD, lecturer

Z EISENBERG, MSC, technician

L LEIB, MD, physician

A HARELL, MD, professor

Nahariya Government Hospital, Nahariya, Israel

$S$ M SHASHA, MD, physician

Biochemistry Department, Weizmann Institute of Science, Rehovot, Israel

S EDELSTEIN, PHD, senior scientist

\section{Jet injection of insulin: comparison with conventional injection by syringe and needle}

Achieving good control of blood glucose concentration in diabetes is important ${ }^{12}$ but may be complicated by patients' reluctance to accept multiple injections of insulin and difficulty in synchronising carbohydrate and insulin absorption. Jet injection is reportedly less painful $l^{3}$ and may provide faster absorption of insulin than standard syringe and needle. ${ }^{34}$

\section{Patients, methods, and results}

Thirteen insulin-dependent inpatient diabetics aged 17-18 were studied. Ten were receiving short-acting and intermediate-acting insulins twice daily and three once daily. All patients were stable for 48 hours before the study and were allocated alternately to group 1 (insulin injected by syringe and needle on day 1 and by injector gun on day 2 ) or group 2 (injector gun on day 1 and syringe and needle on day 2). Jet injections were given using the Med-E-Jet device (Med-E-Jet Limited, Wrexham, Clwyd). Identical insulin doses were administered on both days by the same doctor
15 to 30 minutes before breakfast or evening meal. Short-acting and intermediate-acting insulins were injected separately.

On each day blood glucose was measured before meals, one hour after meals, and before retiring. Medical staff scored bleeding and insulin leakage from each injection site as none (0), drop (1), and trickle (2). Patients scored pain at the time of injection and pain over the hours after injection as none (0), slight (1), moderate (2), severe (3). Student's $t$ test (paired or unpaired) and Wilcoxon's matched pairs signed ranks test were used as appropriate for statistical analysis.

Complete blood glucose profiles were obtained on nine patients, five in group 1 and four in group 2 . Mean blood glucose values $( \pm S E M)$ were initially similar in the two groups $(8.4 \pm 1.1 \mathrm{mmol} / 1$ and $9.6 \pm 1.4 \mathrm{mmol} /$ $(151 \pm 20 \mathrm{mg} / 100 \mathrm{ml}$ and $173 \pm 25 \mathrm{mg} / 100 \mathrm{ml})$ respectively) (NS). By 24 hours the mean blood glucose concentration had fallen in the group treated initially with the syringe but had risen in the group treated with the injector gun $(6.0 \pm 0.8 \mathrm{mmol} / 1$ versus $13.3 \pm 2 \cdot 1 \mathrm{mmol} / 1(108 \pm 14 \mathrm{mg} / 100 \mathrm{ml}$ versus $239 \pm 38 \mathrm{mg} / 100 \mathrm{ml}))(\mathrm{p}<0.01)$. After a further 24 hours, following the change in injection technique, mean blood glucose values had again risen with jet injection but fallen with syringe injection $(8 \cdot 7 \pm 3.2 \mathrm{mmol} / 1$ versus $9 \cdot 8 \pm 2 \cdot 0 \mathrm{mmol} / \mathrm{l})(157 \pm 58 \mathrm{mg} / 100 \mathrm{ml}$ versus $176 \pm 36 \mathrm{mg} / 100 \mathrm{ml}))(\mathrm{NS})$ On paired testing the change in blood glucose from the fasting value on each of the study days was significantly different between the two techniques before bedtime $(n=9 ; p<0.01)$ and fasting the next day $(n=9 ; p<0.05)$ (figure).

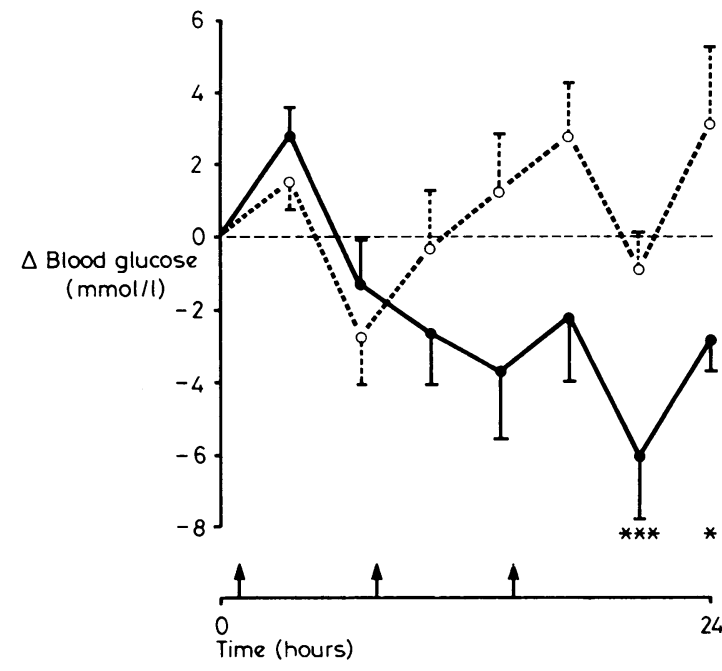

Change in blood glucose $( \pm$ SEM) from fasting value at beginning of day after injection by syringe (O) and gun(o). Main meals indicated by arrows. Significance of differences: $* \mathrm{p}<0.05 ; * * * \mathrm{p}<0.01$. (Blood glucose: $1 \mathrm{mmol} / 1 \approx 18 \mathrm{mg}$ $100 \mathrm{ml}$.).

Total scores after injection by syringe and gun respectively were 21 versus 9 for immediate pain, but 5 versus 13 for delayed pain. Bleeding was scored 19 versus $31(\mathrm{p}<0.05)$ and insulin leakage 17 versus 14 . Overall six patients preferred the syringe and needle, four preferred the jet injector gun, and three were ambivalent.

\section{Comment}

The results clearly showed a rise in blood glucose values at 24 and 48 hours when using the injector gun but a corresponding fall when using the conventional syringe. Thus the effect of insulin given by jet injection was shorter lasting than an equivalent dose given by syringe. Absorption may be faster after jet injection owing to dispersion of the insulin, which may be a useful advantage of the technique. In this small study, however, the differences in blood glucose values between the two methods over the hours immediately after injection were not significantly different. The results emphasise that adjustment of insulin dosage will probably be necessary when altering the method of insulin administration. The advantage of less immediate pain with the injector gun was offset by more delayed pain and also more bleeding. From the relatively few injections received the patients expressed no clear preference for this expensive new technique.

This study provided no definite evidence to favour use of this particular injector gun over conventional syringe and needle. This conclusion may need to be revised when the results of studies of insulin absorption are available.

We are grateful to the British Diabetic Association for financial aid. RW 
was in receipt of a research grant from Newcastle AHA(T) for part of the study period. We also thank Mrs J Harrison, J Thompson, and Dr P Smith for help and Mr R J Atkinson, of Med-E-Jet, for advice and encouragement.

1 Tchobroutsky G. Relation of diabetic control to the development of microvascular complications. Diabetologia 1978;15:143-52.

2 Pirart J. Diabetes mellitus and its degenerative complications: a prospective study of 4,400 patients observed between 1947 and1973. Diabetes Care 1978;1:168-88, 252-63.

${ }^{3}$ Cohn L, Hingsom RA, Narduzzi JV, Seddom JM. Clinical experience with jet insulin injection in diabetes mellitus therapy: a clue to the pathogenesis of lipodystrophy. Ala f Med Sci 1974; ;1:265-73.

${ }^{4}$ Weller $C$, Linder $M$. Jet injection of insulin vv the syringe-and-needle method. F $A M A$ 1966;195:156-9.

(Accepted 3 Fune 1980)

Royal Victoria Infirmary, Newcastle upon Tyne NE1 4LP

R WORTH, MB, MRCP, first assistant in medicine (endocrinology)

J ANDERSON, FRCP, consultant physician and senior lecturer in medicine

Newcastle Area Health Authority (Teaching)

R TAYLOR, BSC, MRCP, registrar in general medicine

University Department of Clinical Biochemistry and Metabolic

Medicine, Newcastle upon Tyne

K G M M ALBERTI, DPHIL, FRCP, professor

\section{Chlorthalidone-induced impotence}

Impaired sexual function may occur with all classes of antihypertensive agents. ${ }^{12}$ Thiazides are rarely incriminated, ${ }^{3}$ however, and chlorthalidone has been implicated in only one, poorly documented case. ${ }^{3}$ We therefore report five cases of sexual dysfunction that were associated with chlorthalidone. Four occurred in participants of the International Prospective Primary Prevention Study in Hypertension sponsored by CIBA. In this double-blind study patients are allocated at random to receive one or two tablets of either placebo or slow-release oxprenolol $160 \mathrm{mg}$ daily. Additional antihypertensive agents except beta-blockers may be used, and we gave chlorthalidone when blood pressure was inadequately controlled.

\section{Case reports}

Case 1-A 56-year-old policeman with blood pressure $150 / 100 \mathrm{~mm} \mathrm{Hg}$ and grade II hypertensive retinopathy was given one tablet of study medication daily. His blood pressure remained high and chlorthalidone $100 \mathrm{mg} /$ day was added. Two months later he complained of severe impotence and decreased libido, which we attributed to oxprenolol, and the study medication was discontinued. When the code was opened, however, he was found to have been taking placebo. Chlorthalidone was then stopped, after which his sexual function improved.

Case 2-A 51-year-old clerk had been adequately treated with methyldopa, propranolol, and chlorothiazide, which he had discontinued for several months. Blood pressure was $200 / 115 \mathrm{~mm} \mathrm{Hg}$, with no evidence of organ disease. While taking chlorthalidone $100 \mathrm{mg}$ and two tablets of study medication daily his blood pressure was $150 / 90 \mathrm{~mm} \mathrm{Hg}$. He complained of severe impotence, however, attributed to chlorthalidone. The diuretic was stopped and his sexual function improved. Six months later he had a myocardial infarction, and when the code was opened he was found to have been taking placebo. Subsequently his blood pressure was controlled by sodium restriction and sexual function was normal.

Case 3-A 58-year-old physician with blood pressure $160 / 105 \mathrm{~mm} \mathrm{Hg}$ took chlorthalidone $100 \mathrm{mg}$ and one tablet of study medication daily. He did not respond, and clonidine $0.15 \mathrm{mg} /$ day was added, which lowered his blood pressure to $120 / 80 \mathrm{~mm} \mathrm{Hg}$. At the time he complained of decreased libido, which he attributed to chlorthalidone. The dose was therefore reduced to $50 \mathrm{mg} /$ day and his sexual function improved. He volunteered for a new trial, and on two occasions on which the dose was raised to $100 \mathrm{mg} /$ day sexua dysfunction promptly recurred. This was not improved by discontinuing clonidine.

Case 4-A 49-year-old farmer with blood pressure $170 / 110 \mathrm{mg} \mathrm{Hg}$ began treatment with chlorthalidone $50 \mathrm{mg} /$ day, increasing to $100 \mathrm{mg} /$ day. Three weeks later he complained of decreased libido and impotence and the drug was stopped. He then took one tablet of study medication daily, to which chlorthalidone $100 \mathrm{mg} /$ day was added. Two weeks later he again complained of impotence, which subsided when the diuretic was stopped.

Case 5-This 62-year-old executive was not participating in the primary prevention study. He had formerly taken propranolol and chlorothiazide, which were stopped because of bradycardia. After several months of chlorthalidone $100 \mathrm{mg} /$ day his blood pressure was normal but he developed severe impotence. Stopping chlorthalidone resulted in the return of sexual function, which remained normal with chlorothiazide $0.5 \mathrm{~g}$ and prazosin $4 \mathrm{mg}$ daily.

\section{Comment}

In four of these patients sexual dysfunction occurred during treatment with chlorthalidone and either oxprenolol or placebo. In all five cases, however, sexual function improved on stopping or reducing chlorthalidone. In case 3 sexual dysfunction recurred twice on increasing the drug to $100 \mathrm{mg}$ daily.

Two patients (cases 2 and 5 ) had taken chlorothiazide with no apparent adverse effect. This agrees with reports that some people may have sexual impairment from one drug known to have this effect yet tolerate another with the same propensity. ${ }^{1}$

Impotence from diuretics is rarely reported, possibly because patients and doctors are too embarrassed to discuss such problems. On the other hand, sexual impairment should not be attributed too readily to certain antihypertensive drugs, since impotence is more common in untreated hypertension than in normal people. ${ }^{4}$ Hence in some hypertensive patients drugs may trigger impotence.

From our findings chlorthalidone-induced impotence may be more common than is generally supposed. Since the drug is often given with an antiadrenergic agent sexual complaints may be attributed to the sympatholytic drug. This may explain the paucity of other reports.

1 Anonymous. Drugs and male sexual function. Br Med F 1979;ii:883-4.

2 Bulpitt CJ, Dollery CT, Carne S. A symptom questionnaire for hypertensive patients. $\mathcal{F}$ Chronic Dis $1974 ; 27: 309-23$.

3 Anonymous. Med Lett Drugs Ther 1977;19:81-2.

4 Bulpitt CJ, Dollery CT, Carne S. Change in symptoms of hypertensive patients after referral to hospital clinic. Br Heart $\mathcal{F} 1976 ; 38: 121-8$.

(Accepted 18 fuly 1980)

Department of Medicine and Hypertension Clinic, Hadassah University Hospital, Mt Scopus, Jerusalem, Israel

J STESSMAN, MD, lecturer

D BEN-ISHAY, MD, associate professor

\section{Unprecedented rise in incidence of infantile hypertrophic pyloric stenosis}

The exact cause of infantile hypertrophic pyloric stenosis is not known but the condition probably occurs when genetically predisposed infants are exposed to a precipitating environmental factor. The incidence in the United Kingdom is widely quoted as two to three cases per thousand live births, ${ }^{1}$ but fluctuations around these figures have been reported. The incidence in the Central Region of Scotland during the past 10 years rose dramatically from an average $2 \cdot 1 / 1000$ $(1970-7)$ to $5 \cdot 2 / 1000$ in 1978 and $8 \cdot 8 / 1000$ in 1979 . This last is the highest figure recorded in the world. I have analysed the 31 cases that occurred in 1979 to try to find a cause for this rise.

\section{Methods and results}

The Central Region of Scotland (population 271 810) is a well-circumscribed area, part rural, part industrial. It is served by Stirling and Falkirk district general hospitals, where virtually all deliveries occur and to which all paediatric hospital referrals are made. The paediatric department is run as a single unit. The senior staff did not change during the 10 years under review. Infants with hypertrophic pyloric stenosis are seen initially by the medical paediatricians, diagnosis is made by palpation of the pyloric tumour at a test feed, and a second opinion is sought before the infant is referred to the general surgeon. All cases included in this series were confirmed at operation.

The numbers of live births each year (figure) were taken from the hospital records and the region's statistics department, the figures agreeing to within 30 births for each year. The table shows the incidence of infantile hypertrophic pyloric stenosis during 1970-9. This differed significantly 